\title{
The Effect of Brand Trust as Extrinsic Characteristics on Young Consumers' Product Preferences: An Experimental Study *
}

\author{
Assist. Prof. Dr. Gulnil Aydin \\ Assoc. Prof. Dr. Aybeniz Akdeniz Ar \\ Bandırma Onyedi Eylül University,
}

Faculty of Economics and Administrative Science, Business Administration

Department, Marketing Division, Bandirma/Balikesir, Turkey

Assist. Prof. Dr. Elif Dogan Savas

Balikesir University, Faculty of Engineering and Architecture,

Department of Food Engineering, Balikesir, Turkey

Doi:10.19044/esj.2018.v14n25p91 URL:http://dx.doi.org/10.19044/esj.2018.v14n25p91

\begin{abstract}
Purpose: This study was carried out in order to be able to evaluate the effects of intrinsic (quality, taste, smell, etc.) and extrinsic (brand, packaging, country of origin, etc.) characteristics in product preferences and quality perceptions and to understand the importance of brand trust as an extrinsic characteristic in preferences.

Design / Methodology: In the study, the evaluations of the university students about the intrinsic and extrinsic characteristics of the cocoa hazelnut cream brands were investigated. In the experimental study with the participation of 50 students, the effects of the intrinsic and extrinsic characteristics on product preferences and quality perceptions were evaluated with the help of the blind and visibility tests applied to participants.

Findings: As a result of the research, it was seen that participants changed their evaluations positively after seeing the brand, which they trust, regarding to the intrinsic characteristics evaluations that they have made without seeing the brand and the package and they diversified their perceptions positively regarding to the intrinsic characteristics for the brands that they trust and like the packaging.
\end{abstract}

Research Limitations / Implications: The fact that the number of samples taken for the research in the experimental studies is not too high is a constraint

- This work was presented as a paper at Uşak I. IASOS International Congress of Applied Social Sciences,2017/09/22. 
on the evaluation of the results. For this reason, the basic suggestion for future studies is to conduct the research with a wider number of the samples.

Originality / Value: This experimental study is important as it reveals the result that the perceptual factors remain at the forefront for the customers about food products.

Keywords: Young Consumer Behavior, Brand Trust, Intrinsic and Extrinsic Characteristics, Product Preferences, Young Consumers, Perceived Product Quality

\section{Introduction}

The increases in the diversity of food products on the market lead the consumers to buy products with higher expectations (Clemons, 2008). Different factors influence consumers' product evaluations. For example, consumers sometimes exhibit different behavioral patterns in a hedonic manner under the influence of hedonic reactions (Varela, Beltran and Fiszman, 2014). In recent years, many studies have been conducted on consumers to understand their preferences, especially in food products, about which qualities they consider and which way they follow. The consumer's preferences for food products or their different motivations tried to be diagnosed (Honkanen and Frewer, 2009; Espinoza-Ortega et al., 2016). In purchasing decisions, it is possible to evaluate them as effective product-oriented attributes as intrinsic and extrinsic properties. While the intrinsic characteristics are more indicative of the physical properties of the product, such as the quality, taste, odor etc., the extrinsic characteristics are described as brand, package, country of origin etc. (Kardeş, Cronley and et al. 2004, Akdeniz Ar \& Kara 2014). The consumers use internal and external factors to make quality definitions of the products (Lee and Lou, 2011).

The way in which the internal and external features of purchasing decisions are weighed/prioritized has created the subject of different studies. The researches, in general, indicate that in the first stage consumers tend to focus on intrinsic features, but on certain conditions, they take extrinsic features to the forefront. It is stated that extrinsic features are taken into account more when conditional factors and image are influential (Godey, Pederzoli et al 2011). Therefore, sometimes consumers use brand knowledge and trust as an extrinsic feature in product evaluations and quality interpretations.

Many businesses act as being aware of the fact that trust plays a vital role in their relations with the customers to be healthy and in long-term, and they move towards to build the actions that will reduce uncertainty in the customer's eyes and build confidence (Kim, Ferrin, and Raghav, 2008). A consumer with a high level of confidence in the brand perceive the products of that brand as of the good quality or trust the brands that he/she believes that it 
has good quality products (Aydın, Ar, and Taşkın; 2014). For this reason, it is stated that there is a mutual relationship between trust and quality perception of the consumers (Rezvani et al., 2012).

In the quality evaluations and preferences of the consumers, the researches to analyze the effects of the intrinsic and extrinsic characteristics were made by considering the different products: such as coffee, fresh vegetables (Jimenez-Guerrero and et. Al, 2012), wine (Mueller and Szolnoki, 2010), soft drinks (Enneking, Neumann and Henneberg, 2005), meat products (Acebron and Dopico, 2000; Bredahl, 2003) and cheese (Veale and Quester, 2009) Product range is important in terms of evaluation of the intrinsic and extrinsic characteristics in the preferences and the perception of the quality. For example, while it is expected that the intrinsic characteristics take precedence over at the hedonic / non-hedonic product evaluations (e.g. cheese, fresh vegetables, etc.), whereas it can be thought that the extrinsic characteristics step in more at the hedonic purchases (Mueller and Szolnoki, 2010). In addition, different studies have shown that extrinsic characteristics can play a role in enhancing or reducing acceptance by a customer of a product that likes in blind testing ( Combris et al., 2009). It is emphasized that the studies are required related to determine that which and on what level the intrinsic and extrinsic characteristics are influential in different customer segments and products (Brecic, Mesic, and Cerzak, 2016).

In the light of the above evaluations, this study was carried out with the aim of evaluating the effects of intrinsic (quality, taste, smell, etc.) and extrinsic (brand, packaging, country of origin, etc.) characteristics in product preferences and quality perceptions of young people and understanding the importance of brand trust as an extrinsic characteristic in their preferences. In this study, cocoa hazelnut cream was chosen as a product category. The main reason for this choice is that the product has the qualification that is predominantly directed at children and adolescents and is an appropriate product qualification for evaluating hedonic purchasing behavior.

In addition, cocoa hazelnut cream is considered as a very important market in terms of brand competition in Turkey. According to Nielsen data, the annual chocolate spread market in Turkey has a volume of 40 thousand tons and 450 million TL. The target of spread chocolate market is children, mothers, and teens and it grows about $10 \%$ each year. In the spread chocolate category, $90 \%$ of the total consumption is in the household and predominantly at the breakfast table. The consumption ratio of the spread chocolate, which enters to the $80 \%$ of the households, is around 3 kilos per household annually. The chocolate production in Turkey was announced as 270 thousand tons per year. The business volume of the sector is stated as 4 billion TL (as of 2015). It is indicated that the leading brand for the year 2016 is Ülker (Dünya, 2016). 


\section{Literature Evaluation \\ The Impact of Intrinsic and Extrinsic Characteristics of the Consumer Evaluations Related To Product Quality}

A lot of studies carried out on the concept of quality, in which the importance is given to product evaluation, draw attention to the multidimensionality of the concept because very different factors can be effective in quality perceptions. For example, starting from the characteristic of the place of the purchase, to when it is purchased (Fandos and Flavion, 2006; Tunçdoğan, and Akdeniz Ar, 2018). Quality is also defined as information or cues received by the consumer about product characteristics when a product is purchased or consumed (Becker, 2000). The consumers are evaluating the usefulness or functionality of the product by taking their needs into account. In this case, it is stated that the quality can be divided into three categories based on product qualities (Fandos and Flavian, 2006):

1. Search quality: This category is a category that is characterized by intrinsic and extrinsic product cues and which is noteworthy and important at the time of purchase.

2. Eating quality: It can be described as the consumers' intrinsic cues that are important for organoleptic (sensory) quality perceptions, and can only be evaluated when the product is consumed.

3. Credence quality: This quality represents both intrinsic and extrinsic cues that can be defined as signs that are not observable in the processes in which the consumer buys and consumes the product.

As a result, when the consumers develop their value judgments about their quality perceptions, it is necessary to distinguish quality concept in two main factor groups (Zeithaml, 1988; Steemkamp, 1997).

$>$ Intrinsic clues that enable objective measurement of quality. At this dimension, the quality should be evaluated with its functional and physical aspect. According to Olson and Jacoby (1972) (transferred by Fandos and Flavian, 2006), intrinsic cues are specific for each product, and the product can not be changed without a change in its structure and disappears when consumed.

$>$ Extrinsic qualities are not part of the product physically but are tips about the product such as brand name or image. These are also known as image variables. Erickson et al. (1984) state that these variables are brand, price, reputation, and country of origin.

The unrecognizable properties of food products during purchasing can mainly include the characteristics such as; hormones, food safety and health, and cholesterol levels (Fandos and Flavion, 2006).

Apart from the distinction between intrinsic and extrinsic qualities in the perception of quality in food products, Sanzo et al. (2001) mentions quality 
perception based on central and peripheral qualities (Fandos and Flavion, 2006):

$>$ Central qualities cover internally characterized dimensions and are described as a category that represents and belongs to both organoleptic (sensory) and food composition (vitamins, minerals, flavor, aroma, color, etc.) and is defined as a category belonging to this structure (Fandos and Flavion, 2006).

$>$ Peripheral qualities correspond to more extrinsic characteristics. The products represent the features considered as alternatives to differentiation in terms of competition: such as brands, labels, design, information about use and utility, authenticity, environmental sensitivity, social and cultural associations.

For this reason, the consumer perceptions are essential in defining the quality concept. In the study carried out by Fandos and Flavion (2006), it was seen that the intrinsic characteristics affected the individuals' intention to purchase a brand. In addition to this, the importance of transferring the information related to the product's extrinsic characteristics in detail to the consumer was also emphasized. Again, in the same study, the effect of the extrinsic characteristics of the products on consumers' brand loyalty was also found to be positive and significant. In addition, it has been concluded that the intrinsic characteristics are influential on the purchasing intention, which can be regarded as short-term, while the influence of the extrinsic characteristics (brand image) is more important on the consumer's loyalty.

In a study conducted by Jimenez-Guerrero et al. (2012) to explore the effects of intrinsic and extrinsic characteristics on consumers' food preferences; it was determined that consumers were mainly affected by intrinsic factors in vegetable selection.

In a similar study by Kathura and Singh (2016); the extent of the intrinsic and extrinsic characteristics of consumers in food preferences are determined. As a result of the research, it has been concluded that the consumers take into consideration both intrinsic and extrinsic characteristics in quality evaluations and purchasing preferences.

In addition to this, some researches show that intrinsic/extrinsic evaluations are taken into account more than product/quality evaluations. However, when it is difficult to evaluate the product or when product familiarity is low, it is stated that extrinsic cues are taken into account (Bredahl, 2003).

\section{Impact of Brand Trust in Product Evaluations}

In purchasing decisions, consumers are required to process a large amount of information for most product categories. This is especially felt in 
product categories where competition is intense - for example in fast-moving consumer goods. The enrichment of the communication environment on a global basis has left the target consumers around the world among the broader product range and evaluation criteria compared to previous times (Kaynak and Kara, 2002, Strasek, 2010; Akdeniz Ar, A. 2012). Most consumers, however, can spend a limited amount of time choosing between different products that are included in the food product category, which they are particularly interested in. In these cases, a number of factors may be considered sufficient in assessing product quality. (Verbeke and Viaene, 1999; Becker, 2000).

The consumer research literature evaluates the process of quality perceptions in two stages. Based on the perceived intrinsic and extrinsic quality indicators (cues), the expectations at the point of purchase are shaped. But in the case of product consumption, how much the expectation was met is searched. Meeting or rejecting the expectations determines the final satisfaction and the decision of purchasing the product again (Oliver, 1980). Several different approaches are used to understand how the quality of the food is perceived by the consumers (Bernues et al., 2003; Banovic et al., 2009). In the broadly accepted "highly qualified approach", quality is a multidimensional phenomenon, and that's why it is defined by the set of qualities perceived subjectively by consumers. In the study conducted by Bredahl (2003), it has been determined that the brand has an effect on both the experienced quality perception and the expected quality level.

According to Enneking, Neumann and Henneberg (2007), the brand awareness and preference play an important role in both product recognition and product quality grading. In a study of taste perception of beer brands, it was observed that participants who know the brand gave higher values in the taste evaluations of the brands they preferred. In addition, in the study, the product preferences, the brand awareness and the packaging were considered to be effective on hedonic responses of the individuals.

In the study conducted by Mueller and Szolnoki (2010), it has been determined that brand information and labeling format (packaging) are the most powerful motivators in the information-based liking and on the basis of visibility test, which was conducted following the blind test. It has been seen that the intention to purchase is also given as information-based liking. When a comparison of the ages of the respondents was made, it was seen that participants who had a higher age and consumed product more frequently were more affected by brand and packaging than the younger ones with relatively less experience.

Similarly, in the Consumer Report magazine's survey of US consumer perceptions, the participants was asked to taste various flavors of jams and to rate and rank them from good to bad (with the criteria as of sweetness, fruit graininess, texture, melting in the mouth). It has been observed that the 
assessments made at this stage overlap with the information provided by the tasting experts. A different group were asked to think and write their evaluations about putting which brand to which sequence and why, after tasting the jam. In this case, the individuals changed their interpretations according to their perceptions of the brand, as they tasted the jams while they were checking up / evaluating the brands (Koç, 2016).

\section{Research Methodology}

The experiment method was used as a data collection tool in the study. Total 50 students, as 25 male and 25 female, from Bandirma Onyedi Eylül University Vocational School participated in the study. Participation in the experiment was based on volunteerism. Detailed information has been given to the students about the purpose and process of the study before the experiment. During and before the data collection period, the following issues were taken into account:

$>$ Participants were chosen from the non-smokers.

$>$ It was desirable that the food is not eaten before the experiment.

$>$ The environment in which the experiment is conducted was provided as clarified from smell, sound, and noise in order to maintain the concentration.

$>$ Participants were taken one by one to ensure that their ideas were not affected by each other. For this reason, the study could be completed with 7-8 students per day. The students were provided to participate in the study by giving them appointments before the study.

$>$ The study was done in the morning hours. This period was chosen because it was thought to be a period with high perceptions for taste.

$>$ In order to perceive tastes related to different brands, the taste in the mouth has been reset with water and bread in the taste transitions.

$>$ Chocolates were provided with a scaled single-use spoon.

$>$ The order of the brands has been changed at each measurement.

In the first and second stages of the experiment, the product managers and the related researches (Acebron and Dopico, 2000) were used to identify intrinsic/extrinsic characteristics of the product evaluations. In addition, indepth interviews conducted at the beginning of the study have provided information on the variables that consumers mainly consider when purchasing products.

\section{Experimental Data Collection Process and Tests Preliminary Phase: Food Analysis}

In the study, firstly laboratory analyzes were carried out on the food samples used in the experiment. The main purpose of making these analyzes is the need for reference values, especially in consumer evaluations of intrinsic 
characteristics. The table below gives information on laboratory values and specifications that are appropriate for the food codex.

Table 1. Product Specifications

\begin{tabular}{|c|c|}
\hline \multicolumn{2}{|c|}{ PHYSICAL SPECIFICATIONS } \\
\hline Color & :Light, Medium, Dark \\
\hline Thickness & $\begin{array}{l}30-100 \text { micron (According to company } \\
\text { request) }\end{array}$ \\
\hline Aflatoxin: B1 & : Max.2,8\%: Min. $0,8 \%$ \\
\hline \multicolumn{2}{|c|}{ CHEMICAL SPECIFICATION } \\
\hline Acid Value & :Max. $1 \%$ \\
\hline Peroxide Value & :Max. $5 \mathrm{Meg} / \mathrm{Kg}$ \\
\hline Aflatoxin: B1 & : Max.2 ppb Total: Max. 4 ppb \\
\hline \multicolumn{2}{|c|}{ MICROBIOLOGICAL LIMITS } \\
\hline T.P.C & :Max. 2000 ( C.F.U /g ) \\
\hline Coliform & : Max. 10 ( C.F.U /g ) \\
\hline Mould & : Max. 50 ( C.F.U /g ) \\
\hline Yeast & : Max. 50 ( C.F.U /g ) \\
\hline E. Coli & : Negative ( C.F.U /g ) \\
\hline Staph. Aureus & : Negative (C.F.U. /g ) \\
\hline Salmonella & : Negative ( C.F.U / $25 \mathrm{~g}$ ) \\
\hline
\end{tabular}

Table 2 shows the results of the analysis of the samples belonging to the brand included in the survey. The samples were evaluated for fat, dry matter content and sugar content. Although it is seen that the contents of the brands are very close to each other in terms of fat and dry matter composition, it is noteworthy that brand $\mathrm{C}$ has a very high value in terms of sugar compared to other alternatives. In this case, the respondents in the experiment should evaluate the brand $\mathrm{C}$ as the sweetest brand.

Table 2. Food Analysis Results of Markets Considered in the Study (chemical properties) *

\begin{tabular}{|c|c|c|c|c|}
\hline Brand & $\begin{array}{l}\text { Fat } \\
\text { (g/100g) }\end{array}$ & $\begin{array}{l}\text { Dry } \\
(\mathrm{g} / 100 \mathrm{~g})\end{array}$ & Matter & Sugar $(g / 100 g)$ \\
\hline A Brand & 30,9 & 82,6 & & 43,1 \\
\hline B Brand & 31,5 & 82,6 & & 44 \\
\hline C Brand & 31 & 83,8 & & 56,4 \\
\hline D Brand & 30,7 & 82,4 & & 42,2 \\
\hline
\end{tabular}

*Analyzes were carried out at Balıkesir University Food Laboratory. The samples used in the experiment were analyzed.

\section{First Stage: Organoleptic Blind Test}

Before the first phase, the general information about the consumption habits of the chocolate hazelnut cream was obtained from the participants. All of the participants stated that they consumed the chocolate hazelnut cream. However, no information on the intensity of use was received. In the first stage, a blind test was applied. The participants tasted of 4 different brands (2 
national, 2 foreign brands). The brands are prevented from seeing by the participants. The eyes of the participants were closed to focus on the taste (especially to neutralize the effects of color and appearance). The evaluations of the participants after the tasting were also marked on the scale with brand codes (Brand A, Brand B, Brand C and Brand D). Qualities asked in the first stage were: taste, smell, slippery in the mouth, etc. After each tasting, the participants were provided with neutralization of the previous taste effects with water and bread.

\section{Second Stage: Visibility Test}

At this stage, the participants were given the opportunity to evaluate the products with their packaging and their brands besides taste and smell. In this experiment, the tasting orders of the brands have been differentiated and it has been stated to the participants that the alignment has been changed. The participants were asked to examine the brands and packaging of the products and even time was given to them for detailed evaluation. The participants examined the jar of the products and they were able to evaluate their contents. In order to avoid perceptual differences, attention has been paid here to the same product basis weight. The comments on the brand evaluations of the respondents were taken after seeing the packaging. Unlike the previous grades on the prepared scale; the evaluations on brand safety, packaging and producer confidence were also added.

The experiment, completed in two steps, took approximately 30-35 minutes per person.

\section{Analysis and Findings of Data}

The results of the blind test, in which the intrinsic characteristics such as hazelnut smell, hazelnut density, nutrient content, etc. related to the cocoa hazelnut cream brands were evaluated, are given in Figure 1 and Table 3. 
Figure 1. Blind Test Results

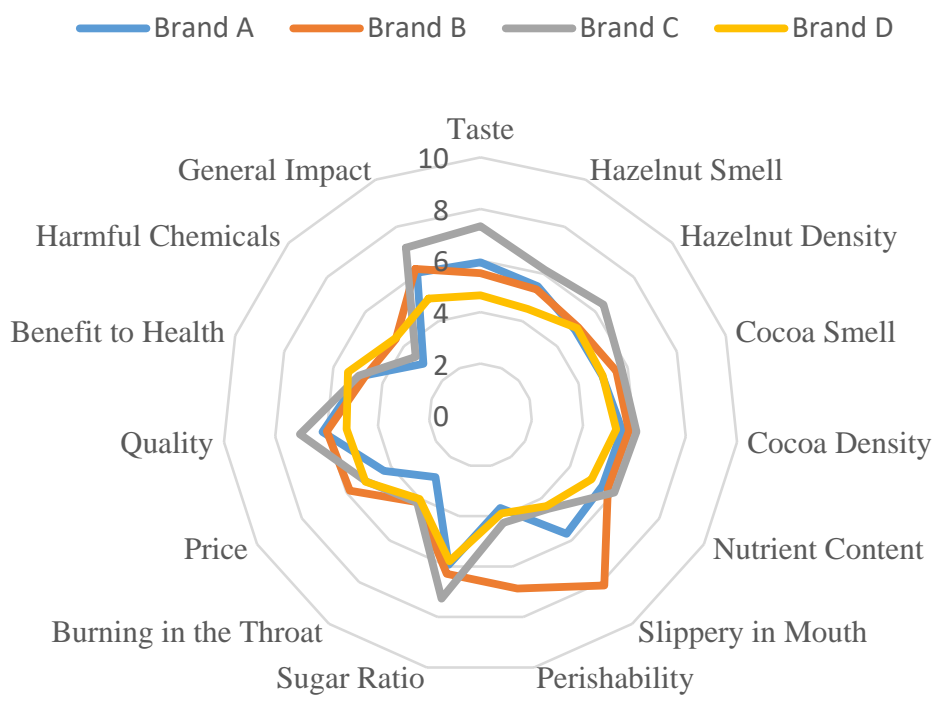

Table 3. The Blind Test Averages of the Respondents Related with the Brands

\begin{tabular}{lllll}
\hline Points (1-10) & Brand A & Brand B & Brand C & Brand D \\
\hline Taste & 5,93 & 5,51 & 7,33 & 4,65 \\
\hline Hazelnut Smell & 5,47 & 5,34 & 6,16 & 4,51 \\
\hline Hazelnut Density & 4,94 & 5,1 & 6,41 & 5,04 \\
\hline Cocoa Smell & 4,96 & 5,54 & 5,76 & 4,98 \\
\hline Cocoa Density & 5,52 & 5,79 & 6,08 & 5,29 \\
\hline Nutrient Content & 5,47 & 5,7 & 5,99 & 4,97 \\
\hline Slippery in Mouth & 5,68 & 8,16 & 4,48 & 4,35 \\
\hline Perishability & 3,68 & 6,87 & 4,26 & 3,89 \\
\hline Sugar Ratio & 5,93 & 6,29 & 7,27 & 5,79 \\
\hline Burning in the Throat & 2,97 & 4,17 & 4,18 & 4,02 \\
\hline Price & 4,32 & 5,85 & 5,12 & 5,15 \\
\hline Quality & 6,16 & 5,99 & 7,04 & 5,22 \\
\hline Benefit to Health & 4,9 & 4,74 & 4,96 & 5,4 \\
\hline Harmful Chemicals & 2,98 & 4,42 & 3,38 & 4,45 \\
\hline General Impact & 6,05 & 6,21 & 7,11 & 4,95 \\
\hline
\end{tabular}

In the ratings based on the averages of the values given by the respondents within the criteria, it is seen that the most popular brand in terms of taste is regarded as the $\mathrm{C}$ brand of the foreign origin. The brands that follow it were Brand A, Brand B, and Brand D. The Brand A again represents the highest average in terms of quality. 
The highest sugar content was identified as Brand C. The C Brand, which has occurred to have the highest taste and quality, has also occurred to have the highest sugar ratio (7.27), allows the interpretation that the hazelnut cream, which is high in sugar, find out to be more delicious. In other words, the respondents can perceive the sweet product as more delicious and of good quality. Although Brand $\mathrm{C}$ has a high rate of quality, the expectation of high price is higher in Brand $\mathrm{B}$. The reason that makes the respondents say that Brand $\mathrm{B}$ is higher in price is explained by having a more slippery texture in the mouth. However, another point that is noteworthy is that the brands, which were found to have the highest taste and quality, were perceived to be more harmful to the health. The liking of the respondents for the products and their opinions about being harmful to their health vary in the opposite direction.

The second stage, the visibility test results are shown in Figure 2 and in Table 4 in detail.

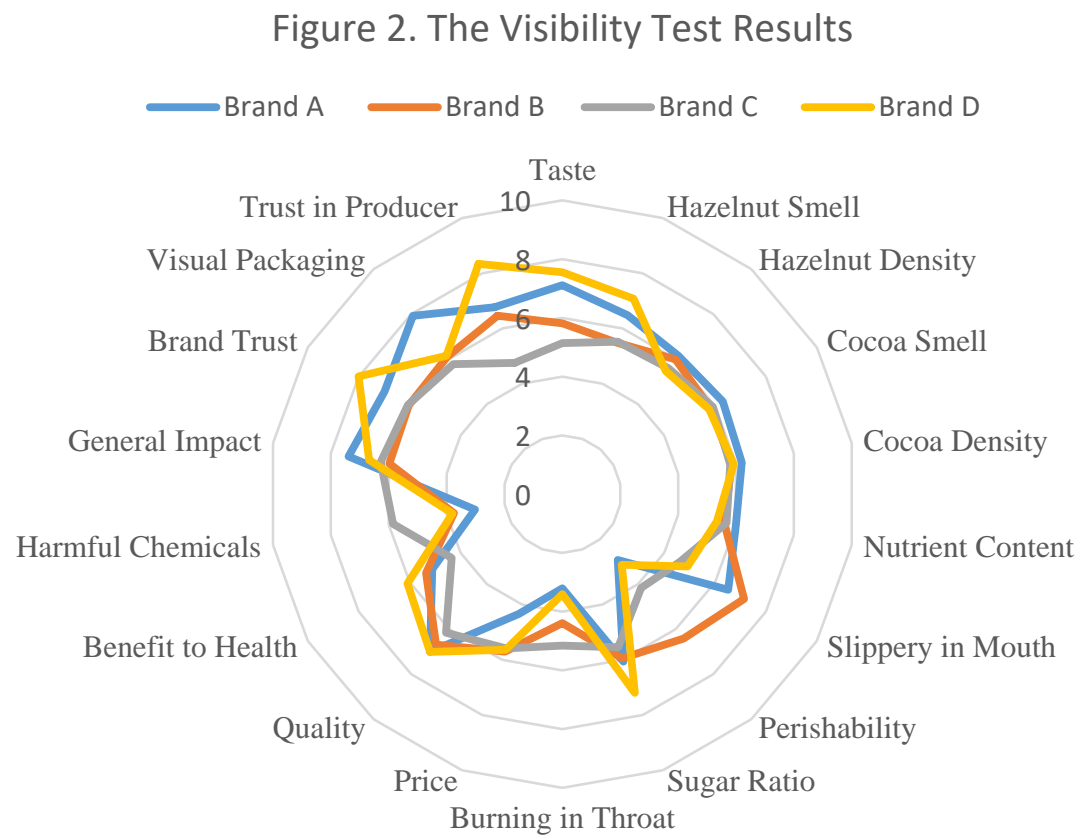


Table 4. The Visibility Test Averages of the Respondents Related with the Brands

\begin{tabular}{lllll}
\hline Points (1-10) & Brand A & Brand B & Brand C & Brand D \\
\hline Taste & 7,11 & 5,81 & 5,14 & 7,55 \\
\hline Hazelnut Smell & 6,48 & 5,48 & 5,52 & 7,08 \\
\hline Hazelnut Density & 6,14 & 5,99 & 5,6 & 5,47 \\
\hline Cocoa Smell & 6,3 & 5,83 & 5,92 & 5,77 \\
\hline Cocoa Density & 6,2 & 5,85 & 5,8 & 5,92 \\
\hline Nutrient Content & 6 & 5,59 & 5,67 & 5,34 \\
\hline Slippery in Mouth & 6,52 & 7,14 & 4,62 & 4,92 \\
\hline Perishability & 2,93 & 6,42 & 4,17 & 3,14 \\
\hline Sugar Ratio & 6,07 & 5,95 & 5,55 & 7,2 \\
\hline Burning in Throat & 3,21 & 4,39 & 5,16 & 3,41 \\
\hline Price & 4,34 & 5,71 & 5,59 & 5,64 \\
\hline Quality & 7,01 & 6,69 & 6,16 & 7,01 \\
\hline Benefit to Health & 5,11 & 5,36 & 4,35 & 6,09 \\
\hline Harmful Chemicals & 3,02 & 3,75 & 5,85 & 3,8 \\
\hline General Impact & 7,39 & 5,98 & 6,28 & 6,68 \\
\hline Brand Trust & 6,99 & 6,04 & 6,07 & 8,01 \\
\hline Visual Packaging & 7,92 & 6,1 & 5,77 & 6,14 \\
\hline Trust in Producer & 6,77 & 6,46 & 4,75 & 8,34 \\
\hline
\end{tabular}

As can be seen from the results shown in Figure 2 and Table 4 above, the respondents in the visibility test reached different results than the blind test. Brand D, where the consumer confidence represents high values, also had the highest scores on taste, quality, sugar and health benefits. The scores in the blind test of the respondents who have no knowledge about the origin and packaging of the brand are explained with the closer numbers to the food analyzes (in terms of sugar and fat ratios), although when the extrinsic characteristics like brand and packaging were added to the evaluations, their quality perceptions have changed. In the criteria that the package is evaluated based on the visual elements, it is seen that Brand A, which is presented to the market with the package variation, represented by higher scores. And this explains the effects of packaging change and innovation on the consumer perceptions of variety. In the study, the visuals of the packaging of the brands were not included because they would make a brand identification. The importance given to the image in the quality evaluations are in parallel with the results of the study carried out by Lam (2001). In this study, it is stated that customers are paying attention to $1 \%$ of the smell, $6 \%$ of the texture of the product and $93 \%$ of the appearance of the product in the newly introduced market ( Koç, 2016). 


\section{Results}

The consumer quality evaluations are known to have an effect on the product preference, satisfaction, and purchase intention. However, the perceived quality is a multi-dimensional content and many different factors can influence the quality perception of the consumers. Besides the characteristics that the product have, the consumer experiences and brand knowledge can also shape these evaluations.

In this study, it is aimed to evaluate the effects of intrinsic (quality, taste, smell, etc.) and extrinsic (brand trust, packaging, etc.) characteristics, which creates a subject to the hedonic purchases of the cocoa hazelnut creams, in product preferences and quality perceptions of the young consumers and to understand the importance of the brand trust as an extrinsic characteristic at the preferences of the young consumers.

As a result of the performed experimental study, it was determined that the participants' evaluations of the intrinsic characteristics of the product without brand information- were majorly parallel to the laboratory results. The extrinsic characteristics (clues) have been found to shape comments on the intrinsic evaluations of the product. The brand, which was preferred in terms of taste and health when the brand evaluations and image-packaging features are taken into consideration, it has left its place to the brands that have collected points in this issue. In the light of these evaluations, it has been seen that the trust in the brand and the image carry a directive feature in the comments related to the intrinsic characteristics.

When the results of both the blank or blind test and visible test are analyzed in detail; when the respondents did not have any ideas about the extrinsic factors like the knowledge, brand, packaging, and price their answers were very similar to the laboratory results in the blank test. On the other hand, when the respondents reached the information such as the brand name, country of origin, ingredients, packaging, and price, their attitude towards the product and brand changed. For this reason, it has become evident that the features of a product or brand image it has created, perception of country of origin, packaging, and price have a very strong effect on the consumers' purchasing intentions or decisions.

However, these results obtained in the study should be supported by the results of the research in which more participants are involved. The fact that the number of the respondents taken for the research in the experiment studies is not too many creates a constraint on the evaluation of the results. For this reason, the basic suggestion for future studies is to conduct the research with a wider number of respondents. 


\section{References:}

1. Acebron, L.B. ve Dopico, D.C. (2000) The Importance of Intrinsic and extrinsic cues to expected and experienced quality: an empirical application for beef. Food Quality and Preference, II pp.229-238.

2. Akdeniz Ar, A.,(2012) Effect of Perceived Values on The Brand Preference and the Purchase Intention.European Scientific Journal.8,17.

3. Akdeniz Ar, A. and Kara, A.(2014) Emerging Market Consumers Country of Production Image Trust and Quality Perceptions of Global Brands Made in China, Journal of Product and Brand Management, 23 (7), 13 Nov.

4. Aydın, G., Akdeniz Ar, A., and Taşkın,Ç. (2014) The Role of Brand Trust on Parents Purchase Intentions of Baby Care Products. Doğuş Üniversitesi Dergisi. 15,2.

5. Banovic M., Grunert G.K., Barreira M.M. ve Fontes A.M. (2009) Beef quality perception at the point of purchase: A study from Portugal. Food Quality and Preference, 20.pp. 335-342

6. Becker, T. (2000), "Consumer perception of fresh meat quality: a framework for analysis", British Food Journal, Vol. 102 No. 3, pp. 158-76.

7. Bernues, A., Olaizola A., and Corcoran K. (2003) Extrinsic attributes of red meat as an indicator of quality in Europe: an application for market segmentation. Food Quality and Preference 14.pp.265-276.

8. Brecic, R., Mesic, Z., ve Cerjak, M. (2016) Importance of Intrinsic and Extrinsic Quality Food Characteristics by Different Consumer Segments, British Food Journal, Vol. 119: 4. pp. 845-862.

9. Bredahl, L. (2003) "Cue utilization and quality perception with regard to branded beef" Food Quality and Preference, 15, pp.65-75.

10. Clemons, E. K. (2008). How information changes consumer behavior and how consumer behavior determines corporate strategy. Journal of Management Information Systems, 25, pp.13-40.

11. Comris,P.Bazoche,E.Giroud-Heraud,S.Issanchou (2009). Food choices: What do we learn from combining sensory and economic experiments? Food Quality Preference, 20 (8),pp.550-557.

12. Dünya, (2016) "Sanset Sagra Türkiye çikolata pazarını büyütecek" www.dunyagida.com.tr adresinden 12.09.2017 tarihinde erişildi.

13. Enneking U., Neumann C. ve Henneberg S. (2007). How important intrinsic and extrinsic product attributes affect the purchase decision. Food Quality and Preference, 18: 133-138.

14. Erickson,Gary M.,Johansson J.K. and Chao, P.(1984). Image Variables in Multi-Attribute Product Evaluations: Country-of-Origin Effects. Journal Of Consumer Research, Vol.11.pp..694-699 
15. Espinoza-Ortega, A., Martínez-García, C.G., Thomé-Ortiz, H. ve Vizcarra-Bordi, I. (2016), "Motives for food choice of consumers in Central México", British Food Journal, Vol. 118 No. 11, pp. $2744-$ 2760.

16. Fandos C., Flavion, C. (2006) Intrinsic and extrinsic quality attributes, loyalty and buying intention: an analysis for a PDO product. British Food Journal, Vol.108, No.8. pp. 646-662.

17. Godey, B., D. Pederzoli, ve diğerleri (2011). Brand and country-oforigin effect on consumers' decision to purchase luxury products. Journal of Business Research. V.65, pp. 1461-1470.

18. Honkanen, P. ve Frewer, L. (2009), “Russian consumers' motives for food choice", Appetite, Vol. 52, No. 2, pp. 363-371.

19. Jimenez-Guerrero J.F, Gazquez-Abad, J.C. ve diğerleri (2012). Estimating Consumer Preferences for Extrinsic and Intrinsic Attributes of Vegetables. A Study of German Consumers. Spanish Journal of Agricultural Research, 10, 3, pp. 539-551.

20. Kardes, F. R., M. L. Cronley, ve diğerleri (2004). The role of selective information processing in price-quality inference. Journal of Consumer Research 31(2).pp. 368-374.

21. Kathura, L. M. ve Singh V. (2016). Product Attributes as Purchase Determinants of Imported Fruits in Indian Consumers, Journal of Food Products Marketing, Vol. 22: 4. pp. 501-520.

22. Kaynak E. and Kara, A.(2002) Consumer perceptions of foreign products: An analysis of product-country images and ethnocentrism, European Journal of Marketing 36 (7/8).pp.928-949

23. Kim, D. J., D. L. Ferrin ve Raghav Rao H. (2008). A Trust-based Consumer Decision-making Model in Electronic Commerce: The Role of Trust, Perceived Risk, and Their Antecedents. Decision Support Systems, Vol.44, I.2, ss. 544-564.

24. Koç, E. (2016). Tüketici Davranışı ve Pazarlama Stratejileri, 7.baskı Seçkin Yayınları.

25. Lee, M. ve Lou, Y.C. (2011), "Consumer reliance on intrinsic and extrinsic cues in product evaluations: a conjoint approach", Journal of Applied Business Research, Vol. 12 No. 1, pp. 21-29.

26. Mueller, S. ve Szolnoki, G., (2010). The Relative Influence of Packaging, Labelling, Branding and Sensory Attributes on Liking and Purchase Intent: Consumers Differ in Their Responsiveness". Food Quality and Preference, V.21, I.7, pp.774-783.

27. Oliver, R.L., (1980) A cognitive model of the antecedents and consequences of satisfaction decisions. Journal of Marketing Research, 17.pp. 460-469. 
28. Rezvani S., Shenyari G., ve diğerleri (2012). Country of Origin: A Study over Perspective of Intrinsic and Extrinsic Cues on Consumers' Purchase Decision. Business Management Dynamics, Vol.1, N.11, ss. 68-75.

29. Steemkamp, J.B. (1997), "Dynamics in consumer behaviour with respect to agricultural and food products", in Wierenga, B., Tilburg, van A., Grunet, K., Steemkamp, J.B. and Wedel, M. (Eds), Agricultural Marketing and Consumer Behaviour in a Changing World, Kluwer Academic Publishers, Dordrecht, pp. 143-88.

30. Sanzo, M.J., Santos-Vijande, M.L.,Vazquez, R., and AlvarezGonzalez, L.I. (2003). The Effect of Market Orientation on BuyerSeller Relationship Satisfaction. Industrial Marketing Management 32 (4). pp. 327-345.

31. Strasek, R. (2010). Empirical testing of correlations between the effects of country-of-origin and consumer perceptions. World's Poultry Science Journal, Vol. 66, March 2010.pp.39-51.

32. Tunçdoğan, A and Akdeniz AR, A. (2018) Distal and proximal predictors of food personality: An exploratory study on food neophilia. Personality Individual Differences. 129. pp.171-174.

33. Varela, P., Beltran, J. ve Fiszman, S. (2014) An alternative way to uncover drivers of coffee liking: Preference mapping based on consumers' preference ranking and open comments, Food Quality and Preference, 32, pp.152-159.

34. Veale R., Quester P. (2016). Tasting quality: The roles of intrinsic and extrinsic cues., Asia Pacific Journal of Marketing and Logistics. 21: 1, pp. 195-207.

35. Verbeke W., Viaene J. (1999) Beliefs, attitude and behavior towards fresh meat consumption in Belgium: empirical evidence from a consumer survey. Food Quality and Preference 10.pp.437-445

36. Zeithaml, V. (1988), "Consumer perceptions of price, quality and value: a means-end model and synthesis of evidence", Journal of Marketing, Vol. 52, pp. 2-22. 